\title{
Analyzing the Impact of Buildings on Surrounding Temperature Observational Environment
}

\author{
DAI Yan-Jie \\ Nanjing University of Information Science \& Technology \\ Nanjing, China \\ daiyanjienj@163.com
}

\author{
QIU Yang-Yang, PIAO Mei-Hua, WANG Yong-Wei \\ Nanjing University of Information Science \& Technology, \\ Yale-NUIST Center on Atmospheric Environment \\ Nanjing, China \\ qiuyangyang_1988@163.com \\ piaomeihua0104@gmail.com \\ wyw@nuist.edu.cn
}

\begin{abstract}
Observational environment has important influence on accurate observation of meteorological elements. Therefore the study of its effect on meteorological elements is of great significance. This paper simulated the impact of a building on surrounding meteorological environment under neutral stratification condition, stable stratification condition and unstable stratification condition by using City Sub-domain Scale Model (CSSM). The results showed that: With the increase of building height, its impact on surrounding air temperature gradually increased. Under neutral stratification condition, the building exerted the largest effect on surrounding environment. When the initial wind speed reached $10 \mathrm{~m} / \mathrm{s}$ and the building was as tall as12 $\mathrm{m}$, the impacted distance to leeside could reach $260 \mathrm{~m}$.
\end{abstract}

Index Terms-Urban building, meteorology observation environment, stratification stability, numerical modeling.

\section{INTRODUCTION}

At present, with the rapid development of cities, populated buildings must have a certain influence on the observation of meteorological elements. Gallo, etc pointed out that the microscale effect is stronger than the meso-scale on the research of the effects of different land use types on daily temperature difference [1]. Russell S. Vose, thought the closer to observation stations, the greater the effect is, when researching reference station network density [2]. Thomas r. Karl, etc studied the impact of different scale cities on meteorological observation [3]. Kukla, etc used climate observation data of 1219 stations in the United States to study the urbanization influences on climate change. According to the population [4], Hua, etc divided cities into three categories as large cities, medium cities and small towns [5], and the results showed that lowest temperature difference between large cities and suburbs can best reflect urban heat island, which could reach $0.74 \mathrm{~K}$ in winter. However, how to quantify city buildings influence to the surrounding station the observation is little researched.

Project supported by the Special Scientific Research Fund of Meteorological Public Welfare Profession of China(Grant No.GYHY201106049).
Based on this, the paper use the community scale numerical model, set different initial temperature stratifications and wind speed conditions, then simulate the impact of buildings on the surrounding temperature, and do a sensitivity test on the changes of building height.

\section{MODEL AND CALCULATION EXAMPLE}

Considering the building scale is small, the problem of the impact on the surrounding temperature should be studied with high precision model. This study selects the city community mode developed by Nanjing University (hereinafter referred to as the "model") [6].The model has been widely used in urban building scale numerical simulation research. Shiguang Miao, etc used the model to simulate meteorological environment and pollution diffusion simulation in the community of Fang zhuang, Beijing [7], and did preliminary verification and comparative analysis on the simulation results, using mooring boat sounding data and electricity board data in this community. The model can be used for numerical simulation research on building meteorological environment.

This paper adopt the ideal example simulation, and the grid number of $\mathrm{x}, \mathrm{y}, \mathrm{z}$ direction is $134,129,35$, the horizontal grid spacing is $10 \mathrm{~m}$, the vertical grid spacing bottom-up ranges from $5 \mathrm{~m}$ to $100 \mathrm{~m}$. Single building with grassland surrounding is set as underlying surface. Building length and width are both $40 \mathrm{~m}$. Building height (h) is $6 \mathrm{~m}, 12 \mathrm{~m}$ and 18 $\mathrm{m}$ respectively. Roofing material is cement. Set ideal weather as the initial field, initial ground temperature is $21.85{ }^{\circ} \mathrm{C}$, and set the direction of the wind as west wind, the initial wind speed (u10) is $2 \mathrm{~m} / \mathrm{s}, 4 \mathrm{~m} / \mathrm{s}$ and $6 \mathrm{~m} / \mathrm{s}, 8 \mathrm{~m} / \mathrm{s}, 10 \mathrm{~m} / \mathrm{s}$ respectively. Set the atmosphere as neutral stratification, convection condition and stable stratification respectively, analysis the effect of buildings on surrounding temperature.

\section{RESULTS ANALYSIS}

According to the result of analysis, the 6-meter-high building had no obvious effect on surrounding air temperature. Therefore the effect of buildings on surrounding air temperature can be studied by analyzing the difference of 
surrounding air temperature between buildings with different height and the 6-meter-high building.

Figure 1 is the distribution of surrounding turbulence and influence to surrounding temperature on the 12-meter-high building, under neutral stratification condition, with different initial wind speed. The figure shows that, when building height is $12 \mathrm{~m}$, it had obvious warming effect on surrounding areas, the maximum value of temperature warming could reach $1{ }^{\circ} \mathrm{C}$. When the wind speed is $2 \mathrm{~m} / \mathrm{s}$, turbulence surrounding the building is $0.08 \mathrm{~m}^{2} / \mathrm{s}^{2}$, the effect of building could reach about $200 \mathrm{~m}$ leeward. When the wind speed increased to $4 \mathrm{~m} / \mathrm{s}$, mechanical turbulence increased to 0.25 $\mathrm{m}^{2} / \mathrm{s}^{2}$ generated due to strong wind shear. Heat generated by buildings transferred in the vertical direction, the influence of temperature leeward was about $180 \mathrm{~m}$. When the wind speed is $6 \mathrm{~m} / \mathrm{s}$, the surrounding turbulence increased to $0.5 \mathrm{~m}^{2} / \mathrm{s}^{2}$ approximately, the effect scope of buildings to surrounding temperature decreased. And when the wind speed is stronger than $6 \mathrm{~m} / \mathrm{s}$, the impact distance leeward increased with wind speed. When the wind speed is $10 \mathrm{~m} / \mathrm{s}$, the impact distance could reach about $260 \mathrm{~m}$. This is because when the wind speed is stronger, the effect of wind speed was larger than turbulence, had become the main factor affecting the temperature, therefore the range affected by the temperature increases with the increase of wind speed.

The effect of building on surrounding meteorological environment under different stratification conditions are compared. Table 1, table 2 and table 3 respectively provided the effective distance of buildings to surrounding air temperature under neutral stratification, convective stratification and stable stratification. Table 1 showed that when the building is $12 \mathrm{~m}$, building had influence to surrounding air temperature. The effect of building on surrounding air temperature decreased with a higher speed of wind when wind is weaker than $6 \mathrm{~m} / \mathrm{s}$. The effect increased with a higher speed of wind when wind is stronger than $6 \mathrm{~m} / \mathrm{s}$. The effect of building on surrounding air temperature was also related to the height of building. The cooling effect caused by building bridging effect was stronger with a higher building, thus surrounding temperature increased less. Table 2 showed that, under convective stratification condition, turbulence is stronger, the influence of building would be transferred in vertical direction, therefore the influence distance on lee side is less than neutral stratification conditions. When building is $12 \mathrm{~m}$, it had obvious influence to surrounding air temperature. There's no big difference of influence distance between 12 meter-high and 18-meter-high building, mainly because of the stronger effect of covering due to the higher building, effects

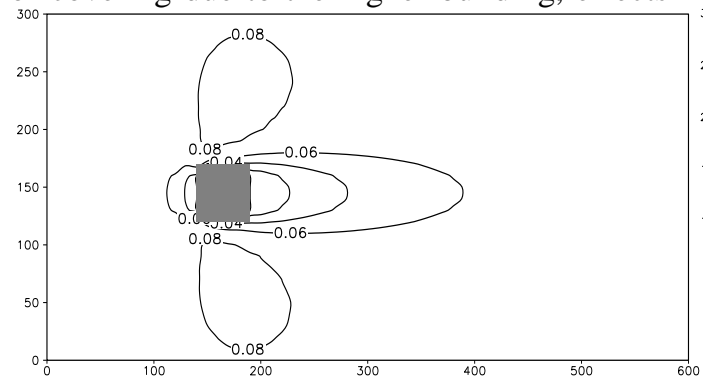

on surrounding temperature was even slightly smaller. Different from neutral stratification and convective stratification, the 6-meter-high building had obvious influence on surrounding air temperature, this is because under stable stratification condition, under stable stratification condition (table 3), because the heat generated by the building is not easy to transfer in the vertical direction, thus had an effect on horizontal direction. When the initial wind speed was $2 \mathrm{~m} / \mathrm{s}$, the environment temperature was about $23.7{ }^{\circ} \mathrm{C}$, it had weak warming effect to leeward, the influence range was only tens of meters. When the initial wind speed was $4 \mathrm{~m} / \mathrm{s}$, the environment temperature increased to $23.8^{\circ} \mathrm{C}$. When the wind speed increased to $6 \mathrm{~m} / \mathrm{s}$, buildings had no obvious effect on the surrounding areas, the heating effect and the shadow covered effect of the buildings just canceled out each other at this time. And when the wind speed was stronger than $6 \mathrm{~m} / \mathrm{s}$, environment temperature decreased with the increasing of wind speed. This is because the wind speed is larger, the cooling effect caused by the shadow shield effect passed with the advection to leeward was more apparent, the influence scope of buildings to surrounding temperature also increased accordingly. When the building is $12 \mathrm{~m}$, it had obvious cooling effect to surrounding air temperature. When building is $18 \mathrm{~m}$, the cooling effect was more obvious.

\section{CONCLUSION}

In this paper, the City Sub-domain Scale Model (CSSM) developed by Nanjing University was used to simulate the effect of initial wind speed variation and building's height variation to surrounding temperature under convection stratification condition, neutral stratification condition and stable stratification. The specific results showed that:

(1)Under neutral stratification condition, the 6-meter-high building had no obvious effect on surrounding air temperature. When building is $12 \mathrm{~m}$, it had obvious influence to surrounding air temperature, the maximum calescence could reach $1{ }^{\circ} \mathrm{C}$, the maximum impact distance could reach $260 \mathrm{~m}$. The effect of building on surrounding air temperature decreased with a higher speed of wind when wind is weaker than $6 \mathrm{~m} / \mathrm{s}$. And the effect of building on surrounding air temperature increased with a higher speed of wind when wind is stronger than $6 \mathrm{~m} / \mathrm{s}$. The effect of building on surrounding air temperature was also related to the height of building. $18 \mathrm{~m}$ high building affected less to air temperature, the cooling effect caused by building bridging effect was stronger with a higher building, thus surrounding temperature increased less, the influence distance was shorter.

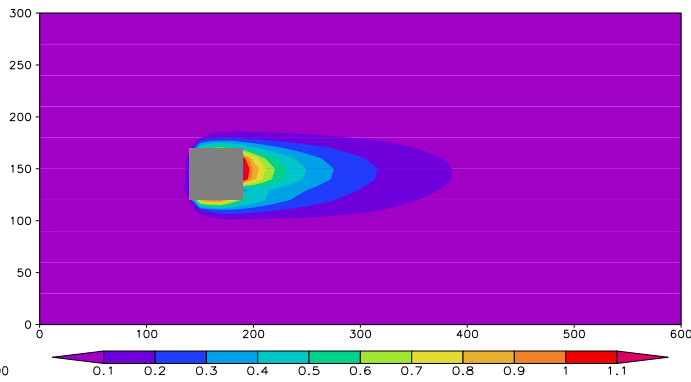


(a) $\mathrm{u} 10=2 \mathrm{~m} / \mathrm{s}$

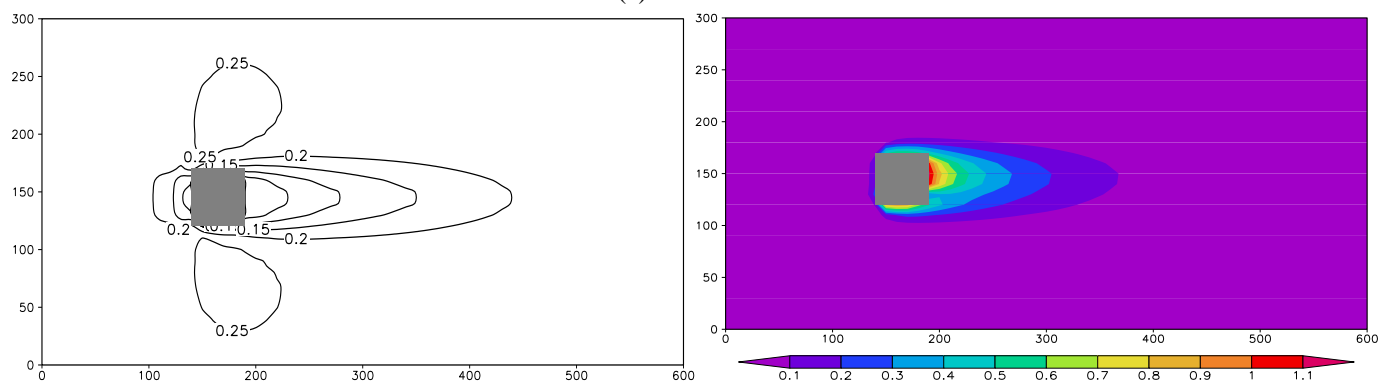

(b) $\mathrm{u} 10=4 \mathrm{~m} / \mathrm{s}$

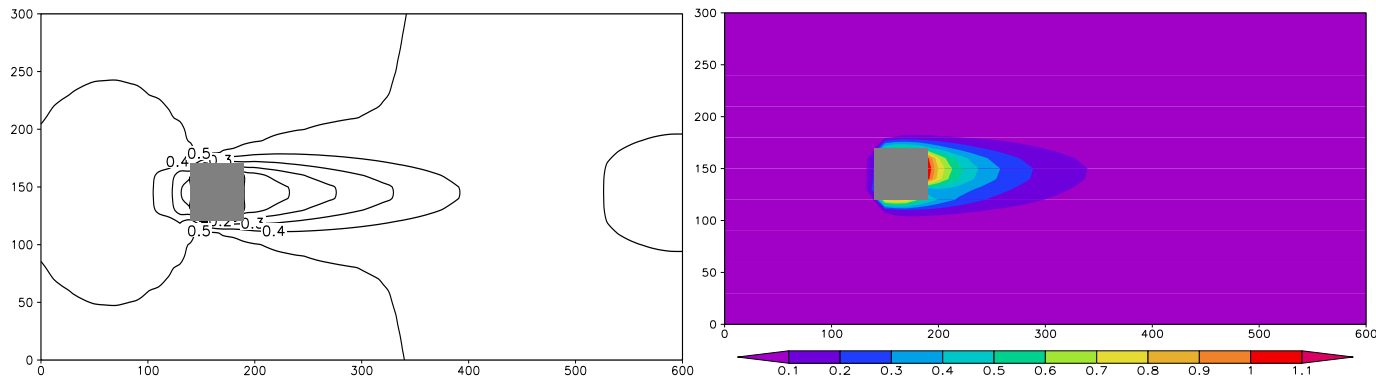

(c) $\mathrm{u} 10=6 \mathrm{~m} / \mathrm{s}$

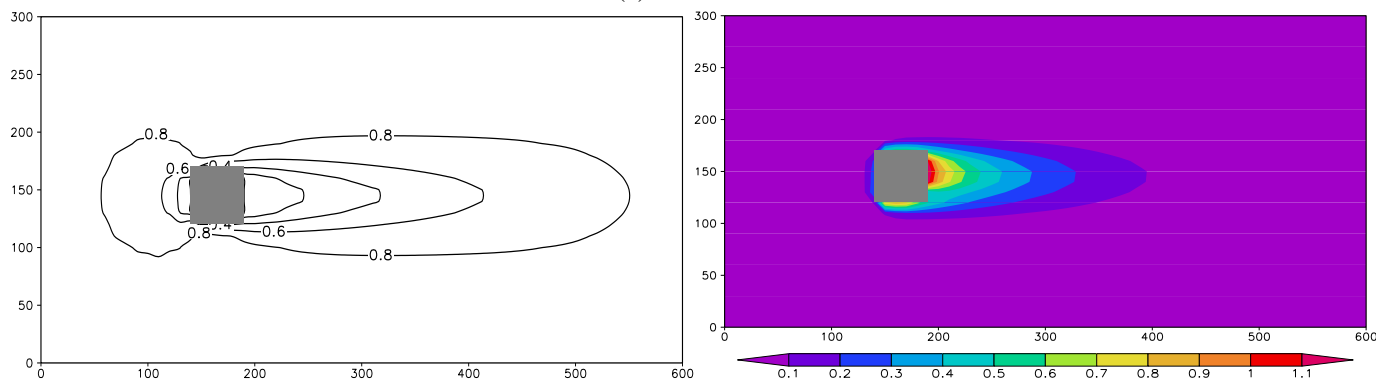

(d) $\mathrm{u} 10=8 \mathrm{~m} / \mathrm{s}$

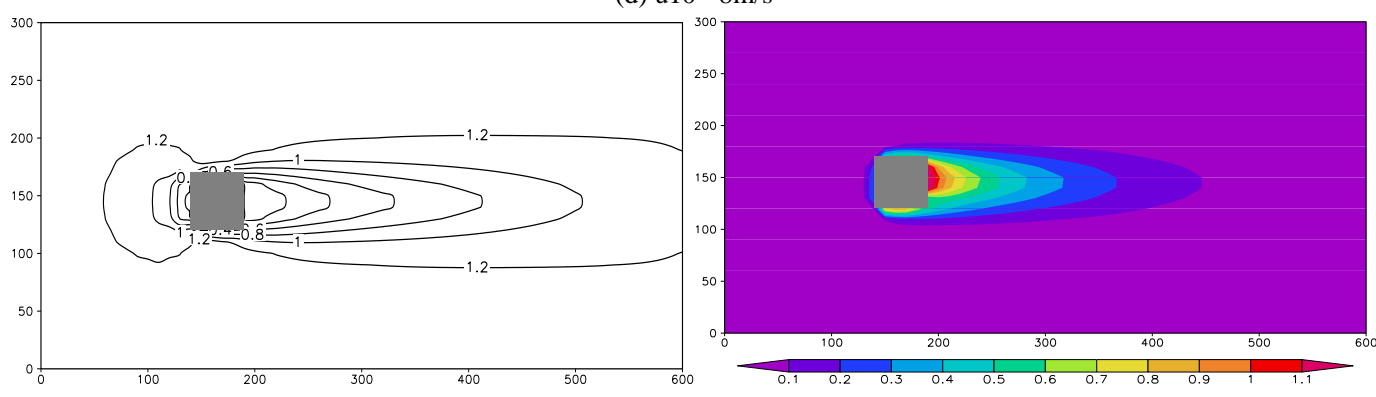

(e) $\mathrm{u} 10=10 \mathrm{~m} / \mathrm{s}$

Fig. 1. Under neutral stratification condition, with different initial wind speed, the distribution of surrounding turbulence and influence to surrounding temperature on the 12-meter-high building

(Left for the turbulence distribution $\left(\mathrm{m}^{2} / \mathrm{s}^{2}\right)$, right for influence to surrounding air temperature $\left({ }^{\circ} \mathrm{C}\right)$ )

TABLE 1. Under neutral stratification condition, with different initial wind speed (u10) and different height (h, m),the buildings affected distance (m) to surrounding air temperature

\begin{tabular}{|c|c|c|c|c|c|}
\hline & 2 & 4 & 6 & 8 & 10 \\
\hline 6 & 0 & 0 & 0 & 0 & 0 \\
\hline 12 & 200 & 180 & 150 & 210 & 260 \\
18 & 170 & 155 & 130 & 200 & 250 \\
\hline
\end{tabular}


TABLE 2. Under convective stratification condition, with different initial wind speed (u10) and different height(h, m),the buildings affected distance (m) to surrounding air temperature

\begin{tabular}{|c|c|c|c|c|c|}
\hline & 2 & 4 & 6 & 8 & 10 \\
\hline 6 & 0 & 0 & 0 & 0 & 0 \\
\hline 12 & 25 & 40 & 60 & 90 & 110 \\
18 & 20 & 40 & 50 & 75 & 110 \\
\hline
\end{tabular}

TABLE 3. Under stable stratification condition, with different initial wind speed (u10) and different height(h, m),the buildings affected distance (m) to surrounding air temperature

\begin{tabular}{|c|c|c|c|c|c|}
\hline & 2 & 4 & 6 & 8 & 10 \\
\hline 6 & 10 & 40 & 0 & 30 & 100 \\
\hline 12 & 30 & 40 & 70 & 80 & 30 \\
18 & 20 & 40 & 80 & 80 & 70 \\
\hline
\end{tabular}

(2)Under convection stratification condition, when building is $12 \mathrm{~m}$, it had obvious influence to surrounding air temperature, the maximum influence distance could be $110 \mathrm{~m}$, much less than that under neutral stratification, because the convective stratification transport heat upward. There's no big difference of influence distance between 12-meter-high and 18-meter-high building, mainly because of the higher the buildings, the stronger the effect of covering, even slightly smaller effects on surrounding temperature.

(3)Under stable stratification condition, the 6-meter-high building had warming effect on surrounding air temperature, the influence distance could be $100 \mathrm{~m}$ when the wind speed is $10 \mathrm{~m} / \mathrm{s}$. When building is higher, it mainly had cooling effect to surrounding temperature, this is because the building shading effect influenced more to air temperature.

\section{REFERENCES}

[1] Gallo, K.P, D.R. Easterling,T.C. Peterson, "The influence of land use/land cover on climatological values of the diurnal temperature range," Papers in Natural Resources, 1996, pp.191.
[2] Vose, R.S., R.L. Schmoyer, P.M. Steurer, et al., The Global Historical Climatology Network: Long-term monthly temperature, precipitation, sea level pressure, and station pressure data, 1992, Oak Ridge National Lab., TN (United States). Carbon Dioxide Information Analysis Center.

[3] Karl, T.R., H.F. Diaz,G. Kukla, Urbanization: Its detection and effect in the United States climate record. Journal of Climate, 1988. 1(11), pp.1099-1123.

[4] Kukla, G., J. Gavin,T. Karl, Urban warming. Journal of Climate and Applied Meteorology, 1986. 25(9), pp.1265-1270.

[5] Hua, L., Z. Ma,W. Guo, The impact of urbanization on air temperature across China. Theoretical and Applied Climatology, 2008. 93(3-4), pp.179-194.

[6] Jiang Wei-Mei, Wang Yong-Wei, Liu Gang, Mutil-Scale Urban Boundary Layer Modelling System, Journal of Nanjing University(Natural Sciences),2007,43(03), pp.221-237

[7] Miao Shi-Guang, Jiang Wei-Mei, Wang Xiao-Yun, et al. Numerical simulation of meteorology and pollutant diffusion in urban sub-domain. ACTA Scientiae Circumstantiae,2002,22(4), pp.478-483. 